\title{
Efeitos de plasma sanguíneo sobre vilosidades, desenvolvimento bacteriano e desempenho de leitões criados em condições de desafio pós-desmame aos 35 dias
}

\author{
Effects of spray dried plasma on villi, bacterial development and performance of piglets \\ reared in challenge conditions post weaning in 35 days old
}

\section{BARBOSA, Fellipe Freitas ${ }^{1}$; SILVA, Francisco Carlos de Oliveira ${ }^{2 *}$; FERREIRA, Aloízio Soares ${ }^{1}$; PUPA, Júlio Maria Ribeiro ${ }^{3}$; BRUSTOLINI, Paulo César ${ }^{1}$ CAMPOS, Priscila Furtado ${ }^{1}$}

\author{
${ }^{1}$ Universidade Federal de Viçosa, Centro de Ciências Agrárias, Departamento de Zootecnia, Viçosa, \\ Minas Gerais, Brasil. \\ ${ }^{2}$ Empresa de Pesquisa Agropecuária de Minas Gerais, Unidade Regional da Zona da Mata, Viçosa, Minas \\ Gerais, Brasil. \\ ${ }^{3}$ Allnutri, Viçosa, Minas Gerais, Brasil. \\ *Endereço para correspondência: fcosilva@epamig.br
}

\section{RESUMO}

Com o objetivo de determinar os efeitos do plasma sanguíneo sobre as vilosidades intestinais e o desenvolvimento bacteriano no intestino delgado, bem como, sobre o desempenho de leitões desmamados aos 35 dias de idade foram distribuídos ao acaso 24 leitões em um experimento com delineamento em blocos, com quatro tratamentos $(0,0 ; 2,5 ; 5,0 \mathrm{e}$ $7,5 \%$ de plasma sanguíneo), seis repetições e um animal por unidade experimental. Foram constatadas diferenças entre tratamentos com relação ao ganho de peso, conversão alimentar, unidades formadoras de colônias de E. coli e altura de vilosidades. Os leitões alimentados com as dietas que continham plasma ganharam mais peso e tiveram menos E. coli no intestino delgado que os leitões alimentados com a dieta controle. Os leitões que receberam as dietas que continham 5,0 ou $7,5 \%$ de plasma apresentaram melhor conversão alimentar em comparação aos animais do controle, e os que foram alimentados com as dietas que continham 2,5; 5,0 ou 7,5\% de plasma receberam, respectivamente, 45,0 ; 75,0 e 70,0\% menos doses de antibiótico em relação aos leitões do tratamento controle. Os níveis de $2,5 \%$ e $7,5 \%$ de plasma na dieta proporcionaram aumentos nas alturas das vilosidades do duodeno e do jejuno dos leitões. A inclusão de plasma sanguíneo em dietas para leitões desmamados aos 35 dias de idade em condições de desafio sanitário tem efeito direto na formação de colônias de $E$. coli e na altura das vilosidades do intestino delgado, bem como, aumenta o ganho de peso e melhora conversão alimentar dos leitões.

Palavras-chaves: desafio, diarréias, Escherichia coli, idade de desmame

\section{SUMMARY}

With the objective to determine the effects of spray-dried plasma on intestinal villi and bacterial growth in the small intestine, as well as on performance of piglets weaned at 35 days old, 24 piglets were randomly assigned in an experimental block design with four treatments $(0.0 ; 2.5 ; 5.0$, and $7.5 \%$ spray dried plasma), six replicates and one piglet per experimental unit. Differences were observed among treatments with respect to weight gain, feed conversion, $E$. coli colony-forming units, and villus height. Pigs fed diets containing spray dried plasma gained more weight and had less E. coli in the small intestine than piglets fed the control diet. The piglets fed the diets containing 5.0 or $7.5 \%$ plasma showed better feed conversion compared to those receiving the control diet. Piglets fed the diets containing $2.5 ; 5.0$ or $7.5 \%$ plasma received $45.0 ; 75.0$, and $70.0 \%$ lesser doses of antibiotics compared to piglets in the control treatment. The levels of $2.5 \%$ and $7.5 \%$ plasma in the diet resulted in increases in villus height in the duodenum and jejunum. The inclusion of spray-dried plasma in diets for health challenged piglets weaned at 35 days of age has a direct effect on the formation of $E$. 
coli colony-forming units and villus height in the small intestine and improves weight gain and feed conversion.

Keywords: age of weaning, challenge, diarrhea, Escherichia coli

\section{INTRODUÇÃO}

O leitão recém-nascido depende da imunidade passiva transmitida pela porca. Após o nascimento, esses leitões recebem imunoglobulinas através do colostro materno, e esta é a principal forma de lhes assegurar a imunidade até o desenvolvimento do próprio sistema imune. O leite materno também pode proporcionar imunidade local, nas paredes intestinais, através das imunoglobulinas (WEAVER et al., 1997).

A falta de imunoglobulinas maternas associada com diversos fatores estressantes no desmame aos 21 dias de idade, bem como os desafios ambientais após o desmame podem resultar em deficiência na ativação do sistema imune próprio do leitão. A ativação do sistema imune pode afetar os processos metabólicos e o crescimento dos leitões devido à interação entre sistema endócrino e sistema nervoso central, mediante a liberação de corticosteróides e tiroxina, que atuam na liberação de citocinas (peptídeos imunoreguladores) pelos leucócitos (KLASING et al. 1991). Têm-se atribuído ao plasma sanguíneo efeitos estimulantes na ingestão de dietas para leitões desmamados aos 21 dias de idade (CAMPBELL et al., 2004), com consequente aumento no ganho de peso e melhora da conversão alimentar. Entretanto, os efeitos benéficos do plasma podem estar também associados à capacidade de aumento da resposta imune na primeira semana após o desmame, aos 21 dias de idade (GATNAU et al., 1993), devido à presença de imunoglobulinas específicas. É possível ainda, que o plasma possa ter efeitos no próprio intestino delgado com a manutenção da integridade das vilosidades intestinais e sobre o controle de unidades formadoras de colônias de Escherichia coli, e isso pode resultar em aumento de ganho de peso e melhora da conversão alimentar dos leitões. Mas é possível, também, que esses efeitos estejam limitados em função do desenvolvimento completo do sistema imune do leitão, que se dá por volta de 35 dias de idade.

Pelo exposto, verifica-se a necessidade de se estudar os efeitos do plasma sanguíneo, independentemente do consumo de ração, sobre as vilosidades intestinais, a formação de colônias de E. coli e o desempenho em leitões desmamados aos 35 dias de idade, criados na creche com desafios.

\section{MATERIAL E MÉTODOS}

O experimento foi conduzido no Setor de Suinocultura do Departamento de Zootecnia do Centro de Ciências Agrárias da Universidade Federal de Viçosa, em Viçosa, Minas Gerais, no período de julho a outubro de 2007.

Foram utilizados 24 leitões machos castrados, híbridos comerciais de alto potencial genético para deposição de carne magra, desmamados aos 35 dias de idade. Os animais foram distribuídos ao acaso em delineamento experimental de blocos ao acaso com quatro tratamentos e seis repetições com um animal por unidade experimental. O critério para formação dos blocos foi o peso do animal ao desmame. Os tratamentos usados foram rações com 0,0 (grupo controle); 2,5; 5,0 e 7,5\% de inclusão de plasma sanguíneo. 
Foram usados os valores de composição de alimentos, bem como os níveis de proteína bruta e energia digestível e os níveis mínimos de cálcio, fósforo total e fósforo disponível das dietas experimentais segundo Rostagno (et al., 2005), e a relação cálcio:fósforo total foi mantida em 1,35 em todas as dietas experimentais.

As dietas experimentais foram compostas com milho, farelo de soja, lactose, óleo, fosfato bicálcico, calcário, sal, mistura de vitaminas, mistura de minerais, lisina, metionina e treonina. O plasma sanguíneo foi usado em equivalente proteico em substituição ao leite em pó usado na dieta do tratamento controle $(0,0 \%$ de plasma sanguíneo). As relações entre os aminoácidos metionina e lisina, treonina e lisina, e triptofano e lisina também foram mantidas de acordo com 0 preconizado em Rostagno et al. (2005). As composições das dietas experimentais encontram-se apresentadas na Tabela 1.

As dietas foram umidificadas $(30,0 \%$ de água mais $70,0 \%$ de ração) e fornecidas aos animais de forma controlada, em quantidades variáveis, em quatro refeições diárias por um período de uma hora por trato, por 12 dias consecutivos, em comedouros pequenos e adaptados para atender as necessidades do experimento. A quantidade de ração fornecida foi determinada em função do consumo dos animais do tratamento um. As sobras de ração diárias dos leitões do tratamento um foram secas e pesadas. Quantidades iguais às consumidas no dia foram fornecidas na refeição do dia seguinte para os leitões de todos os tratamentos, de modo a se assegurar consumos iguais por repetição $\mathrm{e}$ por tratamento. A cada quatro dias as quantidades de ração fornecidas foram aumentadas em 10,0\%. A diferença entre o consumo dos leitões do tratamento um e dos leitões dos demais tratamentos verificada no primeiro dia de experimento foram adicionadas nos últimos quatro dias do experimento.

Aos 35 dias de idade os animais foram desmamados, pesados e transferidos para o galpão creche totalmente fechado e alojados individualmente em gaiolas metálicas, com 1,60m de comprimento $\mathrm{x}$ $1,0 \mathrm{~m}$ de largura. As gaiolas ou baias do tipo suspensas ficavam a uma altura de 0,56m do chão, com pisos e laterais teladas (que permitiam contato visual entre os leitões) e equipadas com bebedouros tipo chupeta e comedouro automáticos.

Os leitões foram criados em condições de desafio sanitário, o que consistiu no alojamento dos leitões em uma sala de creche, sem limpeza nem desinfecção, ocupada com animais mais velhos.

Foi feito aquecimento do ambiente mediante a utilização de lâmpadas incandescentes e a renovação de ar foi realizada pela abertura das portas quatro vezes ao dia, durante uma hora, no momento do fornecimento de ração aos leitões.

Os leitões que tiveram episódios de diarréia e temperatura elevada foram medicados com uma dose diária de 1,0 $\mathrm{ml}$ de antibiótico (enrofloxacina) por via intramuscular. $\mathrm{O}$ número de doses foi adotado como critério para avaliação do índice de diarréia, ou seja, se um leitão apresentou diarréia por mais de um dia consecutivo, este recebeu, a cada dia, dose do antibiótico até a diarréia cessar.

Após o período experimental os leitões foram abatidos de forma humanitária, por meio de insensibilização cerebral, com choque elétrico e posterior sangramento para coleta do conteúdo da ingesta intestinal, no segmento ileal, à $30 \mathrm{~cm}$ da alça ileal. O conteúdo intestinal coletado foi acondicionado em potes plásticos, esterilizados, e imediatamente acomodados em bolsa térmica contendo gelo. Após a coleta do 
Rev. Bras. Saúde Prod. Anim., Salvador, v.13, n.2, p.469-479 abr./jun., 2012 http://www.rbspa.ufba.br ISSN 15199940

$24^{\circ}$ leitão, as amostras foram encaminhadas ao laboratório para se efetuar os procedimentos necessários de contagem de unidades formadoras de colônias (ufc) de E. coli por grama de amostra.

Tabela 1. Quantidades de ingredientes e composições centesimais das dietas de acordo com o nível de plasma

\begin{tabular}{|c|c|c|c|c|}
\hline \multirow{2}{*}{ Ingredientes } & \multicolumn{4}{|c|}{ Níveis de plasma (\%) } \\
\hline & 0,0 & 2,5 & 5,0 & 7,5 \\
\hline Milho & 49,94 & 49,51 & 49,65 & 49,30 \\
\hline Farelo de Soja & 25,70 & 25,70 & 25,70 & 25,70 \\
\hline Leite em pó & 16,20 & 11,90 & 5,50 & - \\
\hline Lactose & 2,33 & 4,96 & 8,88 & 12,20 \\
\hline Plasma Sangüíneo & - & 2,50 & 5,00 & 7,50 \\
\hline Óleo de Soja & 2,42 & 1,82 & 1,46 & 1,18 \\
\hline Fosfato Bicálcico & 1,60 & 1,75 & 1,92 & 2,07 \\
\hline Calcário & 0,70 & 0,70 & 0,71 & 0,85 \\
\hline Sal & 0,35 & 0,35 & 0,35 & 0,35 \\
\hline Mistura de Vitamínas ${ }^{1}$ & 0,15 & 0,15 & 0,15 & 0,15 \\
\hline Mistura de Minerais $^{2}$ & 0,10 & 0,10 & 0,10 & 0,10 \\
\hline L-Lisina HCL (98\%) & 0,231 & 0,256 & 0,285 & 0,293 \\
\hline DL-Metionina (98\%) & 0,152 & 0,168 & 0,176 & 0,182 \\
\hline L-Treonina (98\%) & 0,128 & 0,131 & 0,123 & 0,125 \\
\hline \multicolumn{5}{|l|}{ Composição calculada } \\
\hline $\mathrm{ED}(\mathrm{kcal} / \mathrm{kg})$ & 3500 & 3500 & 3500 & 3500 \\
\hline Proteína bruta (\%) & 21,200 & 21,530 & 21,200 & 21,130 \\
\hline $\mathrm{Ca}(\%)$ & 0,886 & 0,892 & 0,882 & 0,891 \\
\hline Ptotal $(\%)$ & 0,652 & 0,661 & 0,658 & 0,660 \\
\hline Pdisponível (\%) & 0,482 & 0,491 & 0,488 & 0,490 \\
\hline $\mathrm{Na}(\%)$ & 0,270 & 0,274 & 0,280 & 0,280 \\
\hline Lisina dig. (\%) & 1,450 & 1,470 & 1,476 & 1,511 \\
\hline Treonina dig. (\%) & 0,913 & 0,926 & 0,930 & 0,952 \\
\hline Triptofano dig. (\%) & 0,247 & 0,250 & 0,251 & 0,257 \\
\hline Met+Cis dig. (\%) & 0,812 & 0,823 & 0,826 & 0,846 \\
\hline Arginina dig. (\%) & 1,055 & 1,134 & 1,206 & 1,280 \\
\hline Valina dig. $(\%)$ & 0,762 & 0,850 & 0,929 & 1,011 \\
\hline Isoleucina $(\%)$ & 0,708 & 0,732 & 0,745 & 0,762 \\
\hline Lactose $(\%)$ & 11,600 & 11,600 & 11,600 & 11,600 \\
\hline
\end{tabular}


As amostras do conteúdo intestinal foram pesadas para determinação da matéria seca. A contagem de ufc/g foi realizada pelos seguintes procedimentos: 1) as amostras foram homogeneizadas por inversão de pontas e o conteúdo foi drenado para um becker, após a lavagem das mucosas mediante a utilização de cinco $\mathrm{ml}$ de água destilada; 2) o conteúdo coletado foi pesado e, posteriormente, foi retirada uma alíquota de um $\mathrm{ml}$, que foi diluído em 10ml de água destilada, e a partir desta diluição foram realizadas outras diluições até se atingir a diluição de $1: 10.000 .000 ; 3)$ desse conteúdo foi retirado um $\mathrm{ml}$, que foi inoculado em placas de meio de cultura específico que continha alfa ou beta amilase 4) as placas foram incubadas a $35^{\circ} \mathrm{C}$ por 24 horas e após este período foram realizadas as contagens de E. coli. Os resultados foram expressos na base 10 de ufc E. coli por grama (g) de matéria seca da amostra.

$\mathrm{O}$ intestino delgado foi dissecado e clivado em sessões transversais de dois centímetros no duodeno, no jejuno e no íleo. Os fragmentos, imediatamente, após coletados foram imersos em solução fixadora (solução de Bouin) e, posteriormente, foram fixados por 24 horas a $4^{\circ} \mathrm{C}$ em glutaraldeído $2,5 \%$ em tampão fosfato $(0,1 \mathrm{M}, \mathrm{pH} 7,4)$ onde permaneceram por 24 horas. Após este período, os fragmentos foram desidratados em série de concentrações crescentes de etanol (70 a 100\%). Após a desidratação, as amostras dos segmentos intestinais foram recortadas em fragmentos de $1,0 \mathrm{~cm}$, diafanizados em benzol e incluídos em parafina. Utilizou-se de um micrótomo para a obtenção de seções com sete $\mu \mathrm{m}$ de espessura, de modo que entre uma seção e a subsequente, utilizada para leitura, foram eliminadas 30 seções. Os cortes foram colorados pela técnica da hematoxilina e eosina e, posteriormente, preparados na forma de cortes histológicos, em lâminas, no Laboratório de Histologia do Departamento de Veterinária da Universidade Federal de Viçosa.

As medidas de altura de vilosidade foram realizadas através de analisador de imagem em microscópio óptico OLYMPUS BX50, com ampliação de 40 vezes o tamanho da imagem, acoplado ao analisador de imagem "Image Pró Plus 1.3.2" (software), e para cada lâmina foram feitas 30 medidas no Laboratório de Nutrição Animal do Departamento de Zootecnia da Universidade Federal de Viçosa.

Os dados de ganho de peso (GP), conversão alimentar (CA), alturas de vilosidades e ufc de $E$. coli/g de amostra foram submetidos à análise de variância (ANOVA) por meio do Sistema de Análise Estatística e Genética (SAEG), desenvolvido na Universidade Federal de Viçosa - MG (UFV, 2005). As medias de GP, CA e alturas de vilosidades foram comparadas entre tratamentos pelo teste de Dunnet com $\alpha$ $<0,05$. Do mesmo modo, as médias de ufc/g foram comparadas entre tratamentos pelo teste de Dunnet com $\alpha$ $<0,10$. A ANOVA dos dados referentes à ufc/g foi viabilizada transformando-se os resultados pela função $\mathrm{y}=\log \mathrm{x}$, em que $\mathrm{x}$ foi ufc/g. Foram realizadas análises descritivas relacionando-se a ocorrência de diarréias com o número de ufc de E. coli/g de amostra.

\section{RESULTADOS E DISCUSSÃO}

Nos resultados de desempenho, ocorrência de diarréias e colônias de bactérias encontram-se apresentados na Tabela 2, são observadas diferenças significativas entre os tratamentos com relação ao ganho de peso, a conversão alimentar, às alturas de vilosidade no 
Rev. Bras. Saúde Prod. Anim., Salvador, v.13, n.2, p.469-479 abr./jun., 2012 http://www.rbspa.ufba.br ISSN 15199940

duodeno e no jejuno e, também, quanto às ufc de E. coli.

Os leitões que receberam dietas sem plasma sanguíneo ganharam menos peso e tiveram maiores quantidades de ufc de $E$. coli que os animais que receberam dietas com plasma sanguíneo e, ainda, foram observadas menores taxas de conversão alimentar quando comparadas às dos leitões que receberam dietas com 5,0 e 7,5\% de plasma sanguíneo.

Tabela 2. Peso inicial, desempenho, consumo de plasma, doses de antibióticos, colônias de $E$. coli e vilosidades intestinais de leitões desmamados aos 35 dias de idade em função dos tratamentos

\begin{tabular}{|c|c|c|c|c|c|c|}
\hline \multirow{2}{*}{ Parâmetros } & \multicolumn{4}{|c|}{ Tratamentos (nível de plasma sanguiíneo - \%) } & \multirow{2}{*}{$\mathrm{P}$} & \multirow{2}{*}{$\begin{array}{l}\mathrm{CV} \\
(\%)\end{array}$} \\
\hline & 0,0 & 2,5 & 5,0 & 7,5 & & \\
\hline Peso inicial (kg) & 12,64 & 12,65 & 12,61 & 12,62 & - & - \\
\hline Consumo de ração $(\mathrm{kg})$ & 7,66 & 7,66 & 7,66 & 7,66 & - & - \\
\hline Ganho de peso $(\mathrm{kg})^{1}$ & $4,94^{\mathrm{a}}$ & $5,68^{\mathrm{b}}$ & $5,95^{\mathrm{b}}$ & $5,78^{\mathrm{b}}$ & 0,009 & 8,7 \\
\hline Conversão alimentar ${ }^{1}$ & $1,47^{\mathrm{b}}$ & $1,35^{\mathrm{b}}$ & $1,29^{\mathrm{a}}$ & $1,32^{\mathrm{a}}$ & 0,048 & 5,4 \\
\hline Consumo de plasma (g) & 0,0 & 191 & 383 & 574 & - & - \\
\hline Dose de antibiótico $\left(\mathrm{n}^{\circ}\right)$ & 20,0 & 11,0 & 5,0 & 6,0 & - & - \\
\hline Dose de antibiótico (\%) & 100,0 & 55,0 & 25,0 & 30,0 & - & - \\
\hline Colônias E. coli (ufc/g) ${ }^{2}$ & $3,8 \times 10^{6 \mathrm{~b}}$ & $1,3 \times 10^{6 a}$ & $4,7 \times 10^{5 a}$ & $1,3 \times 10^{5 \mathrm{a}}$ & 0,072 & 34,6 \\
\hline \multicolumn{7}{|l|}{ Altura de vilosidade no: } \\
\hline Duodeno $(\mu \mathrm{m})^{1}$ & $331^{\mathrm{a}}$ & $377^{\mathrm{b}}$ & $330^{\mathrm{a}}$ & $401^{\mathrm{b}}$ & 0,036 & 12,6 \\
\hline Jejuno $(\mu \mathrm{m})^{1}$ & $300^{\mathrm{a}}$ & $340^{\mathrm{b}}$ & $326^{\mathrm{a}}$ & $346^{\mathrm{b}}$ & 0,050 & 12,9 \\
\hline Íleo $(\mu \mathrm{m})$ & 264 & 282 & 241 & 311 & - & 13,1 \\
\hline
\end{tabular}

${ }^{1}$ Médias seguidas de letras diferentes na linha diferem entre si pelo teste de Dunnet $(\mathrm{P}<0,05)$.

${ }^{2}$ Médias seguidas de letras diferentes na linha diferem entre si pelo teste de Dunnet $(\mathrm{P}<0,10)$.

Os leitões que consumiram dietas com 2,5 e $7,5 \%$ de plasma sanguíneo nas dietas apresentaram vilosidades mais altas que os leitões que receberam dietas sem plasma sanguíneo. Constatou-se, também, que a aplicação de dosagens de antibióticos nos animais submetidos à dieta sem plasma foi, respectivamente, $45,0 \% ; 75,0 \%$ e $70,0 \%$ maior do que as dosagens aplicadas nos animais que receberam as dietas com 2,5; 5,0 e 7,5\% de plasma sanguíneo, respectivamente.

Nenhuma hipótese biológica foi encontrada para explicar por que os leitões alimentados com dietas que continham 5,0\% de plasma sanguíneo não tiveram as vilosidades intestinais regeneradas, uma vez que o nível de $2,5 \%$ e o de $7,5 \%$ de plasma sanguíneo nas dietas possibilitaram regenerações das vilosidades intestinais frente aos mesmos desafios ambientais encontrados pelos leitões alimentados com 5,0\% de plasma nas dietas. A explicação mais plausível pode ser nutricional. A troca, em termos de equivalentes proteicos na forma de proteína bruta entre leite em pó e plasma sanguíneo pode ter causado uma diminuição quantitativa ou qualitativa em termos de soro proteínas (albuminas e 
globulinas) na dieta quando substituiu $5,0 \%$ de leite em pó por plasma sanguíneo. Assim, a quantidade ou qualidade proteica final desse tratamento pode ter sido insuficiente para assegurar a regeneração das vilosidades do intestino delgado dos leitões que consumiram dietas que continham $5,0 \%$ de plasma sanguíneo.

$\mathrm{Na}$ fase pré-desmame, as vilosidades intestinais são altas e bem estruturadas, o que assegura eficiência na absorção de nutrientes. No entanto, no momento do desmame, a depender da idade dos animais e do alimento usado, o tamanho das vilosidades pode ser diminuído, com concomitante aumento das profundidades das criptas e, em decorrência disto, pode ocorrer redução na área de absorção no intestino delgado e aumento na proporção de enterócitos imaturos nos extremos das vilosidades (PLUSKE et al. 1991). Diminuições na altura das vilosidades e aumentos na profundidade das criptas estão relacionadas com os números de enterócitos nas vilosidades e nas criptas, respectivamente. Com as vilosidades menores e as criptas mais profundas, temse menor absorção e maior secreção, o que predispõe o leitão à diarréia pósdesmame (HAMPSON, 1986).

As imunoglobulinas e a albumina podem atuar como fatores de crescimento da epiderme e contribuir para a redução da atrofia das vilosidades intestinais (KING et al., 2008), assim, o plasma sanguíneo (LORA GRAÑA et al., 2010), probióticos (CORREIA et al., 2010), prébióticos (BARROS et al., 2008), o leite em pó e a gema de ovo podem atuar de maneira trófica nas vilosidades do intestino delgado.

Este tipo de mecanismo tem sido relatado com leitões desmamados aos 21 dias de idade ou menos. Leitões desmamados aos 21 dias de idade alimentados com dietas com quantidades de farelo de soja superiores a $20,0 \%$ podem perder conteúdos proteicos da mucosa intestinal e sofrerem sensíveis alterações da profundidade das criptas e na altura das vilosidades intestinais (JIANG et al., 2000; SCHIMIDT et al., 2003, TORRALLARDONA et al., 2003 e LENEHAN et al., 2007). Entretanto, aos 35 dias de idade, mesmo em aleitamento, os leitões já consomem dietas com 20,0\% de farelo de soja e têm-se constatado, ainda, que, até os 28 dias de idade, o sistema digestivo dos leitões pode não ser capaz de produzir quantidades suficientes de amilases, lipases e outras enzimas que degradam os nutrientes contidos nos alimentos de origem vegetal (LORA GRAÑA et al., 2010), mas há evidências de que o completo desenvolvimento do sistema enzimático dos leitões se dê, independentemente do substrato, entre 35 a 42 dias de idade (FERREIRA et al. 2009).

Apesar de não se ter verificado regeneração da mucosa intestinal dos leitões alimentados com 5,0\% de plasma sanguíneo, constatou-se que o ganho de peso, a ocorrência de diarréias e a colonização do intestino delgado por E. coli foram similares aos obtidos com dietas com 2,5 e 7,5\% de plasma sanguíneo e melhores do que os obtidos com dietas sem plasma sanguíneo.

A proliferação de micro-organismos patogênicos no intestino delgado dos leitões desmamados aos 21 dias de idade pode resultar na ocorrência de diarréias, proporcionando queda no desempenho dos animais (BOSI et al., 2001; COFFEY \& CROMWELL, 2001; VAN DIJK et al., 2001, 2002). É possível que este processo também ocorra em leitões com idades superiores, como a dos leitões desmamados aos 35 dias. A partir dos resultados da pesquisa ora relatada constatou-se que houve uma relação direta entre as quantidades de colônias de 
Rev. Bras. Saúde Prod. Anim., Salvador, v.13, n.2, p.469-479 abr./jun., 2012 http://www.rbspa.ufba.br ISSN 15199940

E. coli e a ocorrência de diarréias e ganho de peso. Assim, pode-se inferir que o plasma melhora o desempenho dos animais devido à diminuição da proliferação bacteriana e, provavelmente, também pela regeneração das vilosidades intestinais.

Os leitões que foram alimentados com dietas com 5,0 e $7,5 \%$ de plasma sanguíneo apresentaram melhores conversões alimentares que os que consumiram dietas sem plasma sanguíneo, o que também pode ter sido em função da proliferação bacteriana, visto que os animais estavam em ambientes com desafio e consumiram as mesmas quantidades de dieta. $\mathrm{O}$ controle da proliferação bacteriana pode reduzir a ocorrência de processos inflamatórios e, consequentemente, diminuir o desvio de energia que seria utilizada no crescimento para a manutenção do sistema imune ativado (BOSI et al., 2004; MORETÓ et al., 2008; PÉREZ-BOSQUE et al., 2008; MORETÓ et al., 2009). A exposição a antígenos pode fazer com que o sistema de defesa do animal seja ativado para neutralizá-los antes que estes possam colocar em perigo a vida dos leitões (STEIN, 2008). A expressão de citocinas pró-inflamatórias pode ter sido menor nos leitões dos tratamentos 5,0 e 7,5\%, o que, provavelmente, tenha contribuído para o direcionamento dos nutrientes para produção e não para a manutenção do sistema imune ativado.

Assim, pode-se concluir que a inclusão de plasma sanguíneo em dietas para leitões desmamados aos 35 dias de idade tem efeito direto sobre as ufc de E. coli por grama de amostra no intestino delgado e resulta em diminuição do índice de diarréias, enquanto os níveis de 5,0 e $7,5 \%$ de plasma também melhoram o desempenho dos leitões criados em condições de desafio.

\section{AGRADECIMENTOS}

À Fundação de Amparo à Pesquisa de Minas Gerais FAPEMIG pelo apoio financeiro para realização desta pesquisa.

\section{REFERÊNCIAS}

BARROS, D.S.; CARAMORI JÚNIOR, J.G.; CORREAA, V.S.; ABREU, J.G.; FRAGA, A.L.; MAINARDI, F.; DUTRA, V. Efeito da adição de probiótico e prebiótico sobre o ganho de peso, consumo de ração e ocorrência de diarréia em leitões na fase de aleitamento.

Revista Brasileira da Saúde e Produção Animal [Online], v.9, n.3, p.469-479, 2008.

BOSI, P.; HAN, I. K.; JUNG, H. J.; HEO, K.N.; PERINI, S.; CASTELLAZZI, A.M.; CASINI, L. Effect of different spray dried plasmas on growth, ileal digestibility, nutrient deposition, immunity and health of early weaned pigs challenged with E. coli K88. Asian-Aus.

Journal of Animal Science, v.14, p.1138-1143, 2001.

BOSI, P.; CASINI, L.; FINAMORE, A.; CREMOKOLINI, C.; MERIALDI, G.; TREVISI, P.; NOBILI, F. AND MENGHERI, E. Spray-dried plasma improves growth performance and reduces inflammatory status of weaned pigs challenged with enterotoxigenic Escherichia coli K88. Journal of Animal Science, v.82, p.1764-1772, 2004.

CAMPBELL, J.M.; QUIGLEY III, J.D.; RUSSELL, L.E.; KOEHNK, L.D.

Efficacy of spray-dried bovine serum on health and performance of turkeys challenged with Pasteurella multocida.

The Journal of Applied Poultry Research, v.13, p.388-393, 2004. 
Rev. Bras. Saúde Prod. Anim., Salvador, v.13, n.2, p.469-479 abr./jun., 2012 http://www.rbspa.ufba.br ISSN 15199940

CORREA, V.S; CARAMORI JÚNIOR, J.G.; VIEITES, F.M.; ABREU, J.G.;

BARROS, D.S. Probiótico líquido para leitões lactentes em diferentes idades.

\section{Revista Brasileira da Saúde e}

Produção Animal [Online], v.11, n.3, p.827-837, 2010.

COFFEY, R.D.; CROMWELL, G.L. Use of spray-dried animal plasma in diets for weanling pigs. Pig News and Information, v.22, p.39-48, 2001.

FERREIRA, A.S.; BARBOSA, F.F.; TOKACH, M.D.; SANTOS, M. Spray dried plasma for pigs weaned at different ages. Recent Patents on Food, Nutrition \& Agriculture, v.1, p.231-235, 2009.

FRANK, J.W.; CARROLL, J.A.; ALLEE, G.L.; ZANNELLI, M.E. The effects of thermal environments and spray-dried plasma on the acute-phase response of pigs challenged with lipopolysaccharide. Journal of Animal Science, v.81, p.1166-1176, 2003.

HAMPSON, D. J. Alterations in piglet small intestinal structure at weaning. Veterinary Science, v.40, p.322-340, 1986.

JIANG, R.; CANG, X.; STOLL, B.; FAN, M.Z.; ARTHINGTON, J.; WEAVER, E.; CAMPBELL, J.; BURRIN, D.G. Dietary plasma protein reduces small intestinal growth and lamina propria cell density in early weaned pigs. Journal of Nutrition, v.130, p.21-26, 2000.

KING, M.R.; MOREL, P.C.H.; PLUSKE, J.R.; HENDRIKS, W.H. A comparison of the effects of dietary spray-dried bovine colostrums and animal plasma on growth and intestinal histology in weaner pigs. Livestock Science, n.119, p.167-173, 2008.
LENEHAN, N.A.; DEROUCHEY, J.M.; GOODBAND, R.D.; TOKACH, M.D.; DRITZ, S.S.; NELSSEN, J.L.; GROESBECK, C.N.; LAWRENCE, K.R. Evaluation of soy protein concentrates in nursery pig diets. Journal of Animal Science, v.85, p.3013-3021, 2007.

LORA GRAÑA, G.; FERREIRA, A.S.; SILVA, F.C.O.; LORA GRAÑA, A.; ARAÚJO, W.A.G.; PEREIRA, C.M.C. Plasma sanguíneo em dietas sem antibióticos para leitões desmamados aos 21 dias de idade. Revista Brasileira da Saúde e Produção Animal [Online], v.11, n.3, p.815-826, 2010.

MORETÓ, M.; MIRÓ, L.; POLO, J.; RUSSELL, L.; CAMPBELL, J.; WEAVER, E.; CRENSHAW, J.; PÉREZ-BOSQUE, A. Oral porcine plasma proteins prevent the release of mucosal pro-inflammatory cytokines in rats challenged with $S$. aureus enterotoxin B. Digestive Disease Week, v.134, 17-22, 2008.

MORETÓ, M.; PÉREZ-BOSQUE, A. Dietary plasma proteins, the intestinal immune system, and the barrier functions of the intestinal mucosa. Journal of Animal Science, v.87, p.92-100, 2009.

NOFRARÍAS, M.; MANZANILLA, E.G.; PUJOLS, J.; GIBERT, X.; MAJO, N.; SEGALES, J.; GASA, J. Effects of spray-dried porcine plasma and plant extracts on intestinal morphology and on leukocyte cell subsets of weaned pigs. Journal of Animal Science, v.84, p.2735-2742, 2006. 
Rev. Bras. Saúde Prod. Anim., Salvador, v.13, n.2, p.469-479 abr./jun., 2012 http://www.rbspa.ufba.br ISSN 15199940

OWUSU-ASIEDU, A.; BAIDOO, S.K.; NYACHOTI, C.M.R.R.;

MARQUARDT, R.R. Response of early-weaned pigs to spray-dried porcine or animal plasma-based diets supplemented with egg-yolk antibodies against enterotoxigenic Escherichia coli. Journal of Animal Science, v.80, p.2895-2903, 2002.

OWUSU-ASIEDU, A.C.; NYACHOTI, M.; MARQUARDT, R.R. Response of early-weaned pigs to an enterotoxigenic Escherichiacoli (K88) challenge when fed diets containing spray-dried porcine plasma or pea protein isolate plus egg yolk antibody, zinc oxide, fumaric acid, or antibiotic. Journal of Animal Science, v.81, p.1790-1798, 2003.

PÉREZ-BOSQUE, A.; MIRÓ, L.; POLO, J.; RUSSELL, L.; CAMPBELL, J.; WEAVER, E.; CRENSHAW, J.; MORETÓ, M. Dietary plasma proteins modulate the immune response of diffuse gut-associated lymphoid tissue in rats challenged with Staphylococcus aureus enterotoxin B. Journal

Nutrition, v.138, p.533-537, 2008.

ROSTAGNO, H.S.; ALBINO, L.F.T.; DONZELE, J.L. GOMES, P.C.; OLIVEIRA, R.F.; LOPES, D.C; FERREIRA, A.S.; BARRETO, L.S.T.

Tabelas Brasileiras para Aves e Suínos: Composição de alimentos e exigências nutricionais: Viçosa, MG: Universidade Federal de Viçosa, 2005. $186 \mathrm{p}$.

SCHIMIDT, L.S.; NYACHOTI, C.M.; SLOMINSKI, B.A. nutritional evaluation of egg byproducts in diets for early-weaned pigs. Journal of Animal Science, v.81, p.2270-2278, 2003.
STEIN, H.H. Feeding the pig's immune system. Porkworld, v.46, p.209-212, 2008.

TORRALLARDONA, D.; CONDE, M.R.; BADIOLA, I.; POLO, J.; BRUFAU, J. Effect of fishmeal replacement with spray-dried animal plasma and colistin on intestinal structure, intestinal microbiology and performance of weanling pigs challenged with Escherichia coli K99.

Journal of Animal Science, v.81, p.1220-1226, 2003.

TORRALLARDONA, D. Spray dried animal plasma as an alternative to antibiotics in weanling pigs: a review. Asian - Australasian Journal of Animal Sciences, v.23, n.1, p.118-131, 2010.

TOUCHETTE, K.J.; CARROLL, J.A.; ALLEE, G.L.; MATTERI, R.L.; DYER, C.J.; BEAUSANG, L.A.; ZANNELLI, M.E. The effects of plasma, lactose, and soil protein sources fed in a phase 1 diet on nursery performance. Journal of Animal Science, v.80, p.494-501, 2002.

VAN DIJK, A.J.; EVERTS, H.; NABUURS, M.J.A.; MARGRY, R.J.C.F.; BEYNEN, A.C. Growth performance of weanling pigs fed spray-dried animal plasma: A review. Livestock Production Science, v.68, p.263-274, 2001.

VAN DIJK, A.J.; NIEWOLD, T.A.; NABUURS, M.J.; Van HEES, J.; De BOT, P. STOCKHOFE-ZURWIEDEN, N.; UBBINK-BLANKSMA, M.; BEYNEN, A.C. Small intestinal morphology and disaccharidase activities in early-weaned piglets fed a diet containing spraydried porcine plasma. Journal Veterinary Medicine A, v.49, p.81-86, 2002. 
Rev. Bras. Saúde Prod. Anim., Salvador, v.13, n.2, p.469-479 abr./jun., 2012 http://www.rbspa.ufba.br ISSN 15199940

YI, G.F.; CARROLL, J.A.; ALLEE, G.L. GAINES, A.M.; KENDALL, D.C.; USRY, J.L.; TORIDE, Y.; IZURU, S. Effect of glutamine and spray-dried plasma on growth performance, small intestinal morphology, and immune responses of Escherichia coli K88+-challenged weaned pigs. Journal of Animal Science, v.83, p.634-643, 2005.
UNIVERSIDADE FEDERAL DE VIÇOSA - UFV. SAEG (Sistemas de Análises Estatísticas e Genéticas). Versão 8.0. Viçosa, MG: Universidade Federal de Viçosa, 2005.

Data de recebimento: 29/06/2011

Data de aprovação: 23/04/2012 